\title{
Vilse i metoddjungeln Funderingar kring litteraturvetenskapens väsen och berättigande
}

\author{
Av Bärbel Westphal, doktorand i tyska, litteraturvetenskap
}

Länk till presentation av Bärbel Westphal

\section{Inledning}

Sedan upplysningstiden har föreställningen om vad vetenskap egentligen är alltmer präglats av och modellerats efter naturvetenskapens arbetssätt. Naturvetenskaperna verkade ha hittat det enda rätta sättet att få kunskap om världen. Idag, efter ett antal paradigmskiften även inom naturvetenskaperna, är man dock mera medveten om att det är svårt att påstå att säker kunskap kan uppnås överhuvudtaget.[1]

"Filosofer har inga resurser som gör dem istånd att lagstifta om vilka kriterier som måste uppfyllas innan ett kunskapsområde kan anses acceptabelt eller "vetenskapligt". Varje kunskapsområde kan analyseras för vad det är. Det vill säga, vi kan undersöka vilka dess mål är, vilket kan skilja sig från vad som vanligen anses eller uppges som dess mål, och vi kan undersöka de medel som används för att nå dessa mål och vilken framgång som uppnåtts." [2]

Som doktorand inom ämnet litteraturvetenskap ställer jag mig frågan om litteraturvetenskap verkligen är en vetenskap, vilka mål forskningen siktar på, vilka teorier som finns och vilka metoder som används, vilka problem som är ämnesspecifika och vilka resultat man kan förvänta sig av ämnets olika inriktningar. Det kan låta som en alldeles för ambitiös målsättning, men jag anser att dessa frågor i alla fall måste ställas innan man bestämmer sig för ett forskningsfält. Jag tror mig inte kunna finna några definitiva svar på alla mina frågor. En positionering måste däremot kunna försvaras med utgångspunkt från en medvetenhet om andra positioner inom ämnet. Syftet är att utifrån enkla funderingar komma fram till hållbara argument för varför man överhuvudtaget kan och bör syssla med litteraturvetenskap.

Slår man upp en nyare svensk introduktion till ämnet litteraturvetenskap finner man en översikt över ett relativt stort antal forskningsfält. Områdena sträcker sig från intertextualitet, komparation, receptionsteori, via biografisk forskning och litteratursociologi, marxistisk och feministisk litteraturkritik till dekonstruktion och nyhistoricism.[3] Litteraturvetenskap är alltså en disciplin med en bred teoretisk bas. Ämnet har i alla tider påverkats av den filosofiska diskussionen och på så vis skapat sina egna utgångspunkter för att bygga upp teoretiska fundament. Redan med det konstaterandet säger man något om ämnets vetenskapliga status. Frågan är dock huruvida dessa områden enbart är teorier, om de också implicerar målen och i vad måtto de tjänar som metoder, d v s hur teorierna kan omsättas i praktisk litteraturanalys.

Genom att i följande text både utgå från vetenskapsteoretiska begrepp såsom induktion, hypotetisk-deduktiv metod och hermeneutik och genom att ringa in några centrala uttryck inom litteraturvetenskapen såsom fiktion - intention, tolkning - strukturanalys, vill jag komma fram till en försvarbar hållning, försvarbar i förhållande till ämnets vetenskaplighet. Jag är medveten om att dessa begrepp representerar endast ett litet urval aspekter, lika medveten är jag om att det har skrivits hyllmeter om litteraturvetenskapens teorier och metoder som jag inte på något vis kommer att kunna tangera här. Men det är heller inte meningen. Utifrån det anförda citatet ska ett kunskapsområde analyseras "för vad det är". 
Var och en måste ju börja från början och ta de första trevande stegen för att erövra sitt ämne, d v s man analyserar utifrån vad man tror "att det är".

\section{Den positivistiska fåran}

Litteraturvetenskap brukar traditionsenligt inordnas under de vetenskaper som använder hermeneutiken som metod. Dock har även litteraturvetenskapen under andra hälften av 1800-talet kännetecknats av en fas av starkt kritiskt och positivistiskt präglad anda, då forskare gjorde helomvändningen från tolkningens sköna konst till att i huvudsak ägna sig åt statistiska data vad gäller verk och författare, helt i Auguste Comtes anda om det empiriskt iakttagbara som den enda godtagbara utgångspunkten för kunskap. I tysk forskning förknippas den i Berlin och Straßburg mycket inflytelserike Wilhelm Scherer (1841-1886) med denna metod.[4] Scherers förtjänst var därvidlag att peka på sambandet mellan det litterära verket och dess historiska och sociala produktionskontext.

Den positivistiska skolan förkastade subjektiv tolkning och koncentrerade sig på data som kunde samlas in med naturvetenskaplig metod. Dessa sociala och historiska fakta låg till grund för antaganden om en orsak-verkan-kedja för litteraturproduktionen. Detta ledde till en god grund för rent lexikala fakta, men kritiserades redan i början av 1900-talet. Om man nämligen trodde att man därigenom kom ifrån tolkningsproblematiken tog man

förmodligen fel, för det första för att verket fortfarande måste förstås i sig och för det andra för att kopplingen mellan författarens livsdata, verkets tillkomsthistoria och verket i sig inte heller den är självklar.

Ett annat forskningsområde är läsaren själv och de sociala betingelserna för litteraturproduktion och konsumtion, litteratursociologin. Att undersöka läsarvanor har visat sig vara ytterst komplicerat, eftersom rent statistiskt påvisbara och mätbara data måste begränsas till bokutlåning eller bokinköp. De säger inget om läsupplevelsen och kan inte få tag i läsarnas förändrade läsarvanor eller tolkningsmönster. Undersökningar vad gäller kulturproduktion och kulturkonsumtion såsom kulturpolitik är naturligtvis av samhällsideologiskt eller ekonomiskt intresse och därför viktiga, men de fångar inte heller litteraturens inre väsen. Den som alltså inte vill begränsa sig till ren statistik vad gäller litteratur måste söka metoder som kan närma sig själva det litterära verket.

\section{Är hermeneutiken en metod eller en teori?}

Intresset och viljan att tolka den text man just läst fångas upp i begreppet hermeneutik. Det är dock inte lätt att ange vad hermeneutiken exakt kan prestera, då också de olika hermeneutiska skolorna lägger tonvikten på olika aspekter. Om Schleiermacher fortfarande såg textförståelse som reproduktion av den litterära produktionsprocessen och Dilthey märkte ut hermeneutiken som motpolen till det naturvetenskapliga arbetssättet har begrepp som hermeneutisk cirkel och hermeneutisk/historisk differens befästs senast med Gadamers och Jauss arbeten. Alla dessa positioner är dock enligt min mening teoretiska resonemang som inte är så lätta att knyta till någon konkret metod. Man lämnas trots den teoretiska funderingen tämligen ensam med sitt sätt att tolka. På frågan hur forskaren bedriver sin forskning i detalj kommer han förmodligen att säga att han/hon läser. Men ingen kollega, opponent eller betygsnämnd kan någonsin få detaljerad insikt i hur forskaren läser. Det är en subjektiv bedömning och kan i bästa fall konfirmeras genom de resultat man lägger fram på grundval av det urval man har träffat. Forskarsamhället litar så att säga på den enskilde forskarens förmåga att skala fram det för honom viktiga. Och där börjar problematiken: ska man företa en heltäckande eller exemplifierande läsning? Vare sig man gör det ena eller andra kommer man att möta problem. Jag läser, du läser, men hur läser vi? Vi kommer inte från att varje ny läsare har en annan förförståelse och kan missa väsentliga aspekter som t ex allusioner ur bibeln eller skönlitteratur.[5] I värsta fall tunnas förståelsen av verket ut allteftersom tidsgapet mellan verk och läsare blir allt större för varje decennium som går. 
Här skulle man naturligtvis också kunna föra en längre diskussion om ämnets metodik och didaktik på universitetsnivå. Där finns det två aspekter som på sätt och vis kan verka motsäga varandra: när man talar om att varje tolkning är subjektiv, hur förenar man denna insikt med ett metodiskt vetenskapligt arbetssätt? Exemplifieringar av hur ett grundligt exerperande går till på grundval av olika teoretiska synsätt är oerhört värdefulla för högre studienivåer. Även en analysmetod som grundar sig på retoriken är till stor nytta. Definerar man en text som en kommunikativ handling är de retoriska kategorier och kriterier som en första analysmetod utmärkta sätt att komma texten inpå livet.[6] Ämnet skulle förmodligen även må bra av ett samarbete med språkvetenskapen för att t ex tillföra semantiska aspekter på texttolkningen. Detta samarbete har glädjande nog inletts på just vår institution med gemensamma seminarier.

Tillbaka till tolkningsaspekten: i postmoderna tider sägs det ofta vara legitimt att godta varje tolkning eftersom den ändå är subjektiv. Men man ska ha i åtanke att Feyerabend, som myntade uttrycket "anything goes" i första hand åsyftade metoden, inte nödvändigtvis resultaten, som den svenska titeln i hans centrala verk Ned med metodologin ger vid handen.[7] Dessutom vänder Feyerabend sig, om jag har förstått det rätt, mot naturvetenskapens tolkningsföreträde vad gäller giltiga och acceptabla vetenskapliga metoder. En annan sak borde det vara med resultaten. Finns det inte ändå resultat, d v s tolkningar som är antingen ointressanta eller helt enkelt felaktiga? Umberto Eco vänder sig mot den helt öppna läsningen av en text. "[...] die Wörter des Autors [bildeten] ein ziemlich sperriges Bündel handfester Indizien, die der Leser nicht einfach schweigend oder palavernd übergehen darf".[8] Det går m a o inte att hyfsa resultaten genom att utelämna viktiga indicier i texten. Forskarens etik måste vila på en vilja att även framställa sådant som motsäger den egna tesen. Eftersom både textproduktion och textreception är inbäddade i var sina historiska och sociala kontexter är interpretation och tolkning visserligen socialt och historiskt variabel men kan fortfarande inte ske helt godtyckligt. Det finns vissa gränser för hur vi kan gå tillväga för att våra tolkningsresultat ska betraktas som vetenskapliga. Vilka dessa gränser är ligger säkert inte endast i konfirmerandet av empiriskt fastställbara fakta utan beror i hög grad också på den rådande diskursen. Hur öppen är den postmoderna öppenheten egentligen?

Min slutsats är nu att hermeneutiken inte ger detaljerade arbetsanvisningar, i motsats till en naturvetenskaplig metod som ska föra ihop ett stort antal statistiska data eller en mätning. Hermeneutiken visar en mycket grov struktur för de banor vi tänker i när vi långsamt ringar in ett problem och hur vi överhuvudtaget kan närma oss en text och uppnå en textförståelse.

\section{Den induktiva och hypotetiskt-deduktiva metoden}

Om en forskare frågar sig vilka symboler det finns för X måste han eller hon företa en ytterst grundlig läsning. Hur grundlig bör den vara? Forskaren tror då kanske att den induktiva metoden leder till säkra resultat. För att hitta störst antal lexem kan man låta ett dataprogram leta reda på alla inom en viss ram möjliga varianter. Man inser genast att det ställer till med problem: även om en dator inte lär missa något kan den inte se ordens relevans i kontexten och den kan inte upptäcka ironi. Det kan en människa. Anta då att forskaren är mycket grundlig och upptäcker både ironi och kontextbundna eller synonyma uttryck för det han vill visa. På den här punkten ställer sig induktionsproblemet: hur många belägg måste forskaren hitta för att stödja sin hypotes? Den skotske filosofen Hume hävdade att induktion genom repetition är logiskt ohållbar - att tidigare observationer, rationellt eller logiskt inte kan ha någon som helst relevans för ej observerade händelser.[9] Vad händer om hypotesen falsifieras av ett enda motbevis, eller om en kritiker inte anser att de framlagda bevisen duger som förklaring? Då måste man enligt min mening hålla sig till ett sorts rimlighetsantagande, vilket förmodligen är praxis i de flesta litteraturvetenskapliga sammanhang. I praktiken stannar humanister ofta vid att arbeta med empiriska generaliseringar. Är vi inte då tillbaka till samma slutsats som drogs efter förra kapitlet, nämligen att den rådande diskursen avgör vad som är ett acceptabelt resultat? 
Andra ansatser, som en läsning ur ett genusperspektiv brukar vilja visa på underliggande värderingar, t ex om ett verk speglar en kvinnofientlig inställning eller ej. Forskaren kan då hitta si och så många belägg för sin tes. Man kan hitta belägg som både stödjer eller stjälper ett antagande. Det kan sägas motsvara den hypotetiskt-deduktiva metoden. Om texten är entydig: vad har man då sagt om verket? Har man också sagt något om verkligheten? I så fall behövs det teorier som reder ut kopplingen mellan text och verklighet. Ofta är däremot litterära verk som livet självt nämligen inkonsekventa. Då måste resonemanget föras vidare: är verket avsett till att vara motsägelsefullt och vilka slutsatser drar vi av detta?

Min slutsats är att båda dessa metoder förmodligen alltid kommer att ha sina brister, eftersom vi inte kan täcka in helheten utan att bli triviala i våra utsagor, samtidigt som en fokusering på ett enskilt fenomen i texten kan missa helhetsaspekten som ju är viktig i en skönlitterär text. Induktion och deduktion är inte tillräckliga i litteraturvetenskapliga sammanhang utan dessa metoder behöver en teori som stakar ut färdriktningen och som kan postulera vissa antaganden om texter, författare och läsare.

\section{Intention och tolkning}

Eftersom texterna i sig själva är uppbyggda som motsägelsefulla och ett induktivt eller hypotetiskt-deduktivt arbetssätt allena inte leder till tillfredsställande resultat, måste man utgå från att all litterär text trots allt kräver en tolkning eller bearbetning. Den tolkningen kommer att se olika ut beroende på läsarens förståelsehorisont. Vi kommer dessutom förmodligen aldrig fram till vad en författare egentligen menar, om det är det vi är ute efter. Författare behöver inte mena någonting. Inte ens om författaren lägger sig i debatten och säger att han/hon inte menade det eller det. Orden som finns har då inte till fullo gett uttryck åt det författaren menade och då är det ju redan försent. "Vad texten uttrycker vid varje tidpunkt bestäms av dess struktur, och möjligheten finns att ingen version av texten motsvarar författarens intention, d v s uttrycker det han avsåg att uttrycka".110] Verket lever ett eget liv och inbjuder då till skilda tolkningar.

Intentionsbegreppet är dock problematiskt. På grund av Jürgen Habermas stora inflytande på i princip all tyskspråkig forskning inom samhällsvetenskap och humaniora, finns den kommunikationsteoretiska modellen i botten på de flesta litteraturteoretiska resonemangen. Litteratur ses som en kommunikativ handling, varvid man utgår från att sändaren (författaren) faktiskt har en intention, något sorts budskap till mottagaren, som är en läsare. Skillnaden gentemot verbal kommunikation är naturligtvis förskjutningen i tid och rum som gör ett direkt fördjupande eller förklarande omöjligt. Därav den hermeneutiska differensen. En textförståelse kommer emellertid även i den här modellen alltid endast vara en delmängd av den avsedda intentionen.[11] Vad kommunikationsmodellen inte ifrågasätter eller kritiskt granskar är själva intentionsbegreppet som i litteraturen kan te sig på många olika sätt. Litteratur har ju också med historisk (geistesgeschichtlich) utveckling och stilarter såsom berättartekniker att göra. Där finns ett innehåll och en form som samspelar. Som i all konst har sätten att visa och berätta genomgått en stor förändring. En författare kan idag säga sig inte vilja ha en annan intention än att experimentera med sina figurer. Då måste läsaren genomskåda det och från första början dra sina egna slutsatser. "Die Schaubühne als moralische Anstalt" så som Schiller (1784) formulerade det är överspelad. Lärandet betyder då inte som under upplysningstiden att man ska övertygas om en viss åsikt, utan att man ska kunna se saker och ting från olika perspektiv. Eller att figurers handlande är betingat av olika förutsättningar. Man kan t o m lära sig att förstå det man egentligen inte vill acceptera. Intentionsbegreppet kan sträcka sig från barockens pedagogiserande diktning, över mer eller mindre dolda budskap, inåtvända reflektioner, berättelser utan identifikationsobjekt, eller ett minimalistiskt program med brottstycken utan synbart sammanhang fram till aleatoriska experiment och total tystnad såsom i t ex Hugo v. Hofmannthals "Chandos-Krise".[12]

Med den här (mycket rudimentära) uppräkningen blir det tydligt att även s k intentioner är 
tids- och formbundna. Även att inte vilja säga någonting är ett ställningstagande som ligger inbäddat i den teoretiska kontexten som råder för tillfället. Intention kan t o m vara politisk korrekthet eller trendbetingad. Där har tolkningsaktiviteten sin uppgift i att synliggöra avsikten, hur den än må vara beskaffad till form eller innehåll.

\section{Fiktion och tolkning}

Hittills har ett faktum förbisetts, nämligen att litteratur är konst. Konsten är i viss mån autonom, d v s den undandrar sig samhälleliga normer och måsten, den behöver inte säga något om verkligheten, den kan utgöra utkast för ideala och önskade förhållanden, den kan göra uppror. Konst leker, konst är inte till någon omedelbar nytta.[13] Vi undersöker alltså ett fält, där människan söker sig ett fritt utrymme. Litteratur är mötesplatsen mellan fiktion och verklighet och där denna symbios blir till något annat än summan av helheten. Litteratur är samtidigt i grunden tidlös. Denna tidlöshet gör det möjligt för läsaren att återfinna sig i den, långt utöver det tidsbundna som ju också finns där.[14] Den del av tidsbundenheten som finns kan emellertid med hjälp av historiska forskningsmetoder skalas fram och göras synlig.

Då har vi nått fram till en kärnfråga som vi hittills inte har ställt: vad är litteratur? Vi vet att den behövs, vi anar en funktion, vi tror att den är nödvändig. Så länge inte neurofysiologin eller djuppsykologin kan ge klara svar på denna fråga är den lika meningslös som frågan vad en människa är och varför vi överhuvudtaget lever "utkastade" i denna värld.[15] Däremot upphör vi inte att ställa frågor och litteraturvetaren ställer sina frågor till litteraturen. I det fiktionala rummet är ett samtal om de mänskliga betingelserna möjligt, där hittar vi ett fritt spelrum för alternativa handlingssätt och åskådningar. Det är litteraturens dialogicitet. Det är för mig personligen litteraturens centrala mål och funktion. Den är enligt min mening en mycket viktig funktion, i synnerhet som vi lever i ett samhälle där vi tar oss allt mindre tid att verkligen tala med varandra om existentiella ting. På det viset kan litteraturtolkningens användbarhet försvaras. Min slutsats är att tvehågsenheten vad gäller tolkning beror på detta: att det är svårt att "värdera värderingar", att vara normativ, att sätta sig in i den andres läsart och läsupplevelse. Det litteraturvetaren gör, även om han arbetar aldrig så noga med sina källangivelser eller sina analyser, är i grunden inget annat än att hålla ett samtal vid liv. Dialogen mellan tolkningarna är emellertid viktig för oss. Därför har också ett vetenskapligt sätt att närma sig litteraturens område ett berättigande. De vetenskapsområden vi sysslar med legitimeras genom samhällets (inte nödvändigtvis kortsiktiga) behov att ställa just sådana frågor till världen. Det är våra frågor om världen som gör att vi utvecklar vetenskapliga sätt att ringa in de för oss angelägna problemfälten. Den förutnämnda rådande diskursen är alltså inte bara en begränsning utan även en möjlighet.

\section{Tolkning och strukturanalys}

Det finns ett vetenskapligt angreppssätt som är mera deskriptivt, som på sätt och vis har sina rötter i positivismen och som söker litteraturens "naturformer" (Goethe).

Strukturanalysen i modern tid grundar sig på den ryska formalismen. Den inbegriper retoriska och narratologiska analyser som i egentlig mening utgör metoder. Det måste sägas vara av intresse att finna strukturer som analogt med naturvetenskapens begrepp om allmänna lagar återfinns i så gott som all slags litteratur. Kritikerna menar att man då förbiser den estetiska faktorn. Det är möjligt, men det är begränsningens pris. Numera inser man att det inte är omöjligt utan t o m nödvändigt att tillföra tolkning och estetiska aspekter när väl den strukturella analysen är gjord. Den teoretiska utgångspunkten för en strukturanalys är antagandet att verket är en hantverksprodukt. En författare måste oavsett sina eventuella intentioner bygga upp berättelsen efter vissa överväganden. Han lägger ner möda på att få - eller inte få - sammanhang, spänning, introduktion och avslutning etc. Detta synsätt riktar sig till att börja med mer på formen än på innehållet. Men: om man synliggör en struktur kan styrningen påvisas. Det blir tydligt var tyngdpunkterna ligger, hur fälten för det ena eller andra fördelar sig, vilka berättartekniska knep författaren använder 
för att rikta uppmärksamheten åt det ena eller andra hållet. Därmed kan en strukturanalys tjäna som precisering och prövning av läsarten eller den preliminära textförståelsen, som ju alltid föregår varje aktiv metodisk analys. Med den här analysmetoden håller forskaren (förhoppningsvis) huvudet kallt och tittar först på verket enligt de principer som det har gestaltats utifrån. Detta kräver naturligtvis en oerhört noggrann exerpering på mikro - och makronivå, d v s en verklig närläsning kombinerad med ett grepp om helheten.[16] Även här kommer det dock att handla om ett visst subjektivt urval av strukturkriterier. Litteraturvetaren som befattar sig med textens mikronivå måste i sitt arbete inbegripa teorier om språk och lingvistik och kommer att finna att språkets väv är oändligt komplicerad och mångskiftande. Helhetsbilden kommer dock så småningom att utgöra en sorts modell, en bild av verket utifrån vilken man kan dra ytterligare slutsatser t o m kanske om författarens intention, må den vara riktad till formen eller innehållet.

\section{Slutfunderingar}

Varje forskare måste fråga sig själv om målet med sitt arbete, varför han/hon väljer ett visst verk, en viss metod och om detta är en metod.[17] Forskaren måste också ha en teoretisk grund att stå på. Enligt min mening är hermeneutiken inte endast en metod, snarare en teori om hur vårt kunskapssökande går till i stora drag, men den säger ännu inget om hur man exakt går till väga för att söka kunskap och hur fällor och felslut kan undvikas. Det är också lätt att förbise viktiga detaljer i ett ofta alltför omfattande korpus. Där har litteraturämnet mer att göra i att utveckla sina metoder. Forskaren måste emellertid för sig själv besvara frågan med vilket arbetssätt han/hon tror sig finna de mest tillfredsställande svaren. Svar som täcker så mycket som möjligt av det han/hon vill visa och som intresserar just honom/henne. Förmodligen kommer det också att visa sig att det inte är så lätt att använda en enda teori/metod uteslutande och konsekvent, utan att man i praktiken jobbar från flera håll samtidigt. Litteraturvetenskapen måste, liksom samhällsvetenskapen leva med "divergerande ansatser under ett och samma tak", eftersom "samhället inte låter sig inordnas under en allmän teoriapparat på samma sätt som objektiverade naturprocesser".[18]

Hur kan man då försvara att denna disciplin faktiskt är en vetenskap? Jag skulle vilja göra en urskiljning: även om en litteraturvetare inte i lika hög grad använder sig av empiri, statistik, logik eller axiomatiska system, så vilar litteraturvetarens arbete och metod på grundlighet och teoretisk medvetenhet. En litteraturvetare gör mer än att tycka till lite eller att fritt spekulera kring en text som en vanlig läsare eller $\mathrm{t} o \mathrm{~m}$ en tidningsrecensent $\mathrm{i}$ viss mån kan tillåta sig att göra. Kraven på litteraturvetenskapen är de påvisbara citaten ur texten och ett hållbart resonemang under hänsynstagande till den historiska och teoretiska kontexten. Varje betydelsefull textdetalj måste därvidlag redovisas. Likafullt är det ett vetenskapligt ansvar att peka ut det motsägelsefulla. Subjektivitet och s k vetenskaplighet är i denna bemärkelse inga motsatser. En något skrämmande insikt kan naturligtvis vara allas vår bundenhet till den rådande diskursen. Men ändå legitimeras varje vetenskapsområde av samhällets behov. Så länge samhället, alltså vi, har behov att reflektera om sig själv i litteraturen, fyller litteraturvetenskap en viktig funktion.

De olika forskningsområdena bidrar sammantaget till större förståelse för litteraturen och dess villkor. Forskning inom litteraturvetenskapen ökar vår kunskap om världen, människans existensbetingelser och denna konstarts form och funktion. Eftersom litteraturvetenskapen oavlåtligen ifrågasätter sina mål och metoder måste den även sett ur denna aspekt betraktas som vetenskap.[19] Förmodligen kommer litteraturvetarens forskningsresultat att bli av större intresse för andra än för honom/henne själv, eftersom litteraturvetenskap i så hög grad är dialogisk. Resultatet kommer att anammas eller kritiseras av flera efterföljande generationer forskare. Det är ämnets hermeneutik. Litteraturvetaren lägger in sitt bidrag i samtalet om verket. Detta samtal pågår ständigt och kommer inte att sluta så länge den kommunikativa människan finns. 
[1] Om Kuhns begrepp "paradigm" se Alan F. Chalmers, Vad är vetenskap egentligen? Om väsen och status hos vetenskapen och dess metoder, Nora 1995, s 105-116.

[2] Chalmers, s 179.

[3] Staffan Bergsten (red), Litteraturvetenskap. En inledning, Lund 1998.

[4] Se vidare: Dieter Gutzen, Norbert Oellers \& Jürgen H. Petersen, Einführung in die neuere deutsche Literaturwissenschaft: ein Arbeitsbuch, Berlin 1989, s 143 f.

[5] Om Gadamers Heideggerkritik: "Vi måste acceptera att vi aldrig kan frigöra oss från vår förståelsehorisont". Dagfinn Føllesdal, Lars Walløe \& Jon Elster, Argumentationsteori, språk och vetenskapsfilosofi., Stockholm 1993, s 148.

[6] Jürgen Habermas, Kommunikativt handlande. Texter om språk, rationalitet och samhälle, Göteborg 1988.

[7] Paul K. Feyerabend, Ned med metodologin! Skiss till en anarkistisk kunskapsteori, Lund 1977.

[8] Umberto Eco, Zwischen Autor und Text, München 1996, s 30.

[9] Ang. Poppers interpretation av Humes induktionsproblem se Føllesdal, Walløe \& Elster, s 84.

[10] Føllesdal, Walløe \& Elster, s 126.

[11] Om kommunikationsmodeller se: Jürgen Schutte, Einführung in die

Literaturinterpretation, Stuttgart 1997, s $22 \mathrm{f}$.

[12] Hugo von Hofmansthal, Brief des Lord Chandos, 1902.

[13] "Es liegt im Wesen der Kunst, elitär zu sein". Gutzen, Oellers \& Petersen, s 230.

[14] "[...] die Zeitlosigkeit [zeigt sich] schon daran, daß ein fiktional erzähltes Geschehen heute genauso "gilt" wie morgen und in fünf oder fünfzig Jahren, - nämlich immer dann, wenn der Leser die Erzählung liest". Jürgen Petersen, Erzählsysteme. Eine Poetik epischer Texte. Stuttgart 1993, s 22.

[15] "Vi är "kastade" in i världen, hävdar Heidegger. [...] Det är en grundläggande banalitet som metafysisk spekulation länge förbisett. Världen, som vi kastas in i utan personligt val eller föregående kunskap ... var där före oss och kommer att vara kvar efter oss". Om Heideggers "Geworfenheits-begrepp", se Georg Steiner, Martin Heidegger - en introduktion. Göteborg 1994, s 100.

[16] "New Criticism von J.E. Spingarn 1910 geprägte Bezeichnung für [...] rein formalästhetische wertende Form der Literaturwissenschaft in den USA und z.T. England bes. 1930-1960, die in erster Linie werkimmanent von der Autonomie des lit. Kunstwerks als organ.-ästhetischer Einheit ausgeht, durch "close-reading" Form und Stilfragen, Rhythmus und Bild untersucht [...]". Om begreppet "close reading" se Gero von Wilpert, Sachwörterbuch der Literatur. Stuttgart 1989, s 622.

[17] "Methodisch vorgehen heißt, die Ausgangsbedingungen der eigenen Arbeit kennen, ein Erkenntnis- bzw. Handlungsziel definieren und die Prinzipien und Verfahren formulieren, nach denen auf dem projektierten Weg zum Ziel vorgegangen werden soll". Schutte, s 13.

[18] Jürgen Habermas: Samhällsvetenskapernas logik. Göteborg 1988.

[19] "A theory or discipline which purports to be scientific is pseudoscientific if and only if: 1 it has been less progressive than alternative theories over along period of time, and faces many unsolved problems; but 2 the community of practioners makes little attempt to develop the theory towards solutions of the problems, shows no concern for attempts to evaluate the theory in relation to others, and is selective in considering confirmations and disconfirmations". Paul R. Thagard, "Why Astrology Is a Pseudoscience". Martin Curd \& J.A.Cover (red), Philosophy of Science, The Central Issues. New York, London 1998, s 27 - 38. Citatet från s 32. 